with a number of medical students and young doctors, and $I$ have been impressed by their dedication, commitment, enthusiasm and desire to care, but sadly, many seem to have had little or no training in the technique of interviewing a patient or in the skills of counselling. Many medical schools use videos and "sham patients", but some appear not to do so. I have always tried to take either a medical student or a student nurse on domiciliary visits and I feel that young nurses are much better trained in establishing rapport with the patient, and am enormously impressed by their interviewing skills.

I feel that not only our nursing colleagues but social workers and clinical psychologists should be given more time to contribute to teaching these fundamental skills to medical students at the start of their clinical period. If workshops were set up just for two or three days there could be much interchange and dissemination of knowledge.

Sir Desmond Pond said, in the Maudsley Bequest Lecture in 1963 that he knew many doctors, some eminent and distinguished, who had no idea how to talk to a patient. A distinguished clinical psychologist told me that she considered a certain consultant's ward rounds to be so damaging to the patients as to be a "degrading ceremony". It is sad that, although young doctors are so keen and so good, many should be lacking in fundamental skills of counselling and interviewing.

St George's Hospital

JOHN WHITE

Lincoln LN1 IEF

\section{Revista Medico-Chirurgicala}

\section{DeAr SirS}

Our periodical Revista Medico-Chirurgicala(Medical Surgical Journal) is published quarterly and listed in Index Medicus, Biological Abstracts, Excerpta Medica, Chemical Abstracts and other major world indexing services.

Revista Medico-Chirurgicala is the oldest medical journal in Romania (the first issue was in 1887) and is now received by more than 350 universities and medical institutes world-wide. We publish papers in all fields of medicine, general reviews, university news, etc.

Manuscripts of original researches from any country are welcome. The authors should follow strictly the Uniform Requirements for Manuscripts submitted to Biomedical Journals prepared by the International Committee of Medical Journal Editors (British Medical Journal, 1982, 284, 1766-1767 and Annals of Internal Medicine, 1982, 96, 766-771).

Perhaps you could envisage publishing a paper in our journal or could contact other colleagues who would be willing to submit their papers. As a member of the editorial board I should be delighted to receive your contribution.

\section{Revista Medico-Chirurgicala}

Dr TraIan MiHaescu

16 Independentei Boulevard

PO Box 25

Iasi 6600, Romania

\title{
The Derek Ricks Memorial Fund
}

Applications are invited from anyone in the field of paediatric handicap for the Derek Ricks Fellowship. It is envisaged that applicants may be writing a book, developing a piece of equipment, undertaking research, etc. or wishing to visit other centres to further their own expertise. The Fund Administrators will consider any proposal which will ultimately benefit families directly or indirectly.

Further details are available from and applications should be sent to: The Derek Ricks Memorial Fund, Harper House Children's Service, Harper Lane, Radlett, Herts. WD7 7HU. Closing date for formal applications: 31 December 1990. 